\title{
Reflectance measures of grassland biophysical structure
}

\author{
Y. HE $\uparrow$, X. GUO*† and J. F. WILMSHURST $\ddagger$ \\ $\dagger$ Department of Geography, University of Saskatchewan, Saskatoon, \\ SK S7N 5A5, Canada \\ $\$$ Western and Northern Service Centre, Parks Canada, Winnipeg, MB, \\ R3B 0R9, Canada
}

(Received 28 September 2007; in final form 21 February 2008)

\begin{abstract}
Leaf area index (LAI), as an easily obtained variable, has been demonstrated to be a good indicator for estimating vegetation biophysical properties, and is simultaneously well correlated with remote sensing vegetation indices (VIs). The goal of this study is to develop an efficient method to retrieve vegetation biophysical properties based on ground LAI measurements and satellite data, and thus avoid the labour-intensive and time-consuming process for collecting biomass and canopy height in the future. The field data was conducted in Grasslands National Park (GNP), Saskatchewan, Canada and the biophysical properties (i.e. green biomass, dead biomass and canopy height) of the grassland community were collected. Two VIs, the adjusted transformed soil-adjusted vegetation index (ATSAVI) and the renormalized difference vegetation index (RDVI), were derived from SPOT $4 \mathrm{HRV}$ images to estimate LAI and to prepare LAI and biophysical maps for the GNP. The results of the linear regressions demonstrated strong relationships between LAI and both of these selected VIs. However, a detailed assessment of the accuracy of the regression models indicated that the ATSAVI was likely to be better than the RDVI in estimating and mapping LAI for a northern mixed grassland ecosystem. The accuracy of the LAI map, derived from the ATSAVI, was calculated to be $66.7 \%$ and this map represented the spatial distribution of the vegetation acceptably. The significant relationship between measured LAI and the biophysical data solves the difficulty for mapping biophysical information due to insufficient sampling coverage for GNP. Our results demonstrate that, in native prairie ecosystems, reflectance can be used to measure the vegetation biophysical properties and thus to aid management decision making.
\end{abstract}

\section{Introduction}

Effectively managing grassland ecosystems for economic and ecological returns requires that land managers have a good understanding of management effects at large spatial scales. This has always been a challenge due to the inordinate effort required to measure biological community responses in a very dynamic and heterogeneous ecosystem that covers vast areas.

In response to this challenge, range condition assessments have been developed that provide a consistent, albeit qualitative index of the condition of grasslands that can be completed rapidly and, hence, cover large areas (Friedel 1991). While there is

*Corresponding author. Email: xulin.guo@usask.ca 
$0 \quad$ little question of their usefulness for livestock ranchers, extending their utility to other aspects of the grassland ecosystem, such as wildlife populations or soil processes, has been challenging. While this may be attributed to difficulties marrying qualitative assessments to quantitative biological data, the fact remains that information from qualitative range assessments have rarely been used in ecological studies. Nevertheless, quantitative alternatives that offer the same degree of efficiency have been slow to gain popularity (Stohlgren et al. 1997).

The need for information on the biophysical condition (i.e. biomass of green and senescent vegetation, canopy height, shrub stem densities and frequency of bare soil) of grasslands at a landscape scale is great. Non-adaptive approaches to stocking cattle on extensive ranging operations will ultimately result in overgrazing if stocking rates are not frequently adjusted to reflect the range condition. Wildfire management and prescribed burning programs require updated fuel load information for extensive rangelands to be effective. Conservation and government organizations who are also land managers in the Great Plains region need to monitor the structure and composition of their grasslands as habitat for the wildlife they are intending to manage. All of these activities benefit from timely and often quantitative measures of the biophysical properties of a rangeland to inform management decision making.

In theory, reflectance technology should provide suitable measures for grassland ecosystems. Reflectance images either integrate light wavelengths into a limited number of broad 'bands' that correspond to colours or regions of non-visible light or, in the case of hyperspectral imagery, sense and record the reflected wavelengths individually, resulting in hundreds of readings per pixel in every image. There is well-established literature on how to combine bands or wavelengths into 'vegetation indices' (VIs) that, based on the physical properties of the vegetation being measured and the landscape in which they are being measured, reveal vegetation biophysical properties in the image (Rouse et al. 1974, Richardson and Wiegand 1977, Huete 1988, Baret et al. 1989, Qi et al. 1994, Broge and Leblanc 2000, Haboudane et al. 2004). The best known of these is the normalized difference vegetation index (NDVI), which combines the red and near infrared bands and is integrated over time to measure vegetation biophysical properties (Rouse et al. 1974). Many more VIs have been developed that are modifications of the NDVI, or work on a similar principle. Examples of these indices included ratio-based VIs (NDVI, RDVI and MSR), soil-line-related VIs (PVI, SAVI, MSAVI, TSAVI, ATSAVI and SARVI) and chlorophyll-corrected VIs (TVI, MCARI, MCARI1, MTVI1, MCARI2 and MTVI2). The complete names, detailed formulation and proposed advantages about these indices can be found in $\mathrm{He}$ et al. (2007). The exhaustive comparative studies have already been carried out to assess the predictive power of the different optical indices and their sensitivity to various canopy parameters and external factors (e.g. Broge and Leblanc 2000, Haboudane et al. 2004, He et al. 2006). However, the heterogeneous, three-dimensional structure of vegetation, the variable accumulation of litter correlated with landform and community type, seasonal variation in canopy moisture as well as the presence or absence of bare ground in grassland ecosystems, have proven to be insurmountable challenges to most VIs, making them ineffective in native prairie (Asner et al. 2000).

As part of a program to manage a prairie ecosystem for ecological integrity at Grasslands National Park (GNP), located in southeastern Saskatchewan, Canada, we have been measuring the biophysical structure and composition of the grassland 
0 community (including flora and fauna) in relation to reflectance measures from satellite images. The objective of this study is to demonstrate that, in native prairie ecosystems, reflectance can be used to measure the structure and the composition of grasslands and thus avoid the labour-intensive and time-consuming process for collecting biomass and canopy height in the future, and to further indicate that the utility of the imagery can be extended to other management activities, such as fire management, species-at-risk and grazing utilization measures. Specifically, this study sought to use the leaf area index (LAI) as an intermedial variable to indirectly establish the relationships between remote sensing VIs and vegetation biophysical properties (e.g. biomass and canopy height). The theoretic background of this study is that the LAI, as an easily obtained variable, has been demonstrated to be a good indicator for estimating vegetation biophysical properties and is simultaneously well correlated with remote sensing VIs.

\section{Materials and methods}

\subsection{Study area description and site distribution}

The GNP $\left(49^{\circ} 12^{\prime} \mathrm{N}, 107^{\circ} 24^{\prime} \mathrm{W}\right)$ lies within the mixed-grass prairie of the Northern Great Plains (see figure 1). The climate in the study area is semi-arid, average temperatures range from $-12.4^{\circ} \mathrm{C}$ in January to $18.3^{\circ} \mathrm{C}$ in July and average precipitation is approximately $350 \mathrm{~mm}$ per year (Environment Canada 2000). All

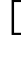
study sites were located in the west block of GNP, which was historically used for grazing with some limited cultivation for crops and hay. The soils in this area are brown Chernozemic clay loam soils. GNP consists of upland, slopeland and valley

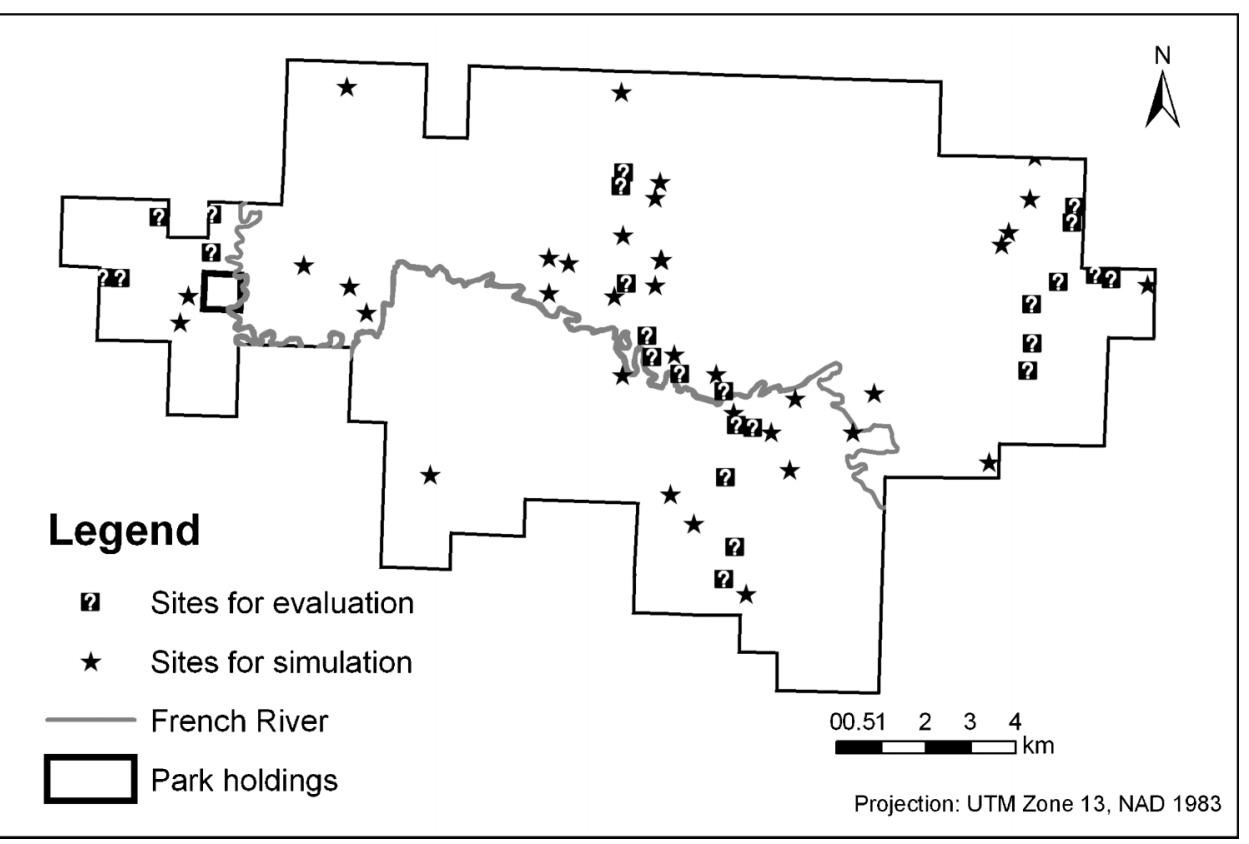

Figure 1. Map of the study area: Grasslands National Park, southern Saskatchewan, Canada, located at the international boundary of Canada and the United States. Stars indicate the study sites for model simulation and question marks indicate the study sites for model evaluation. 
grasslands, and the dominant native grasses are June grass (Koeleria macrantha), needle-and-thread grass (Hesperostipa comata), blue grama (Bouteloua gracilis) and western wheat grass (Pascopyrum smithii). In addition, exotic grasses, forbs and shrubs are widely distributed throughout the study area. This park and surrounding pasture areas are ideal for biophysical assessment studies of vegetation communities because of the variety in management practices in the area.

During June of 2005, the 60 randomly selected sampling sites were visited for the LAI, biomass and canopy height data. These sites included rangelands, conserved native prairie and invaded grasslands, distributed over the upland, sloped and valley area. At each of these sites, field sampling was conducted along two $100 \mathrm{~m}$ transects that ran perpendicular in the north-south and west-east directions, intersecting in the centre to form a cross. The georeferenced coordinates for each of the cross centres were determined, within a $6 \mathrm{~m}$ accuracy, using a handheld global positioning system (GPS). The transect locations were permanently marked on the ground and these coordinates were later digitized into the Park's geographic information system (GIS) data layers.

\subsection{Field measurements and sample processing}

Along each of the $100 \mathrm{~m}$ transects, canopy height was collected at $10 \mathrm{~m}$ intervals and biomass was collected at $20 \mathrm{~m}$ intervals using a $20 \times 50 \mathrm{~cm}$ daubenmire frame. Clipped fresh biomass was sorted into four groups: grass, forb, shrub and dead materials. The four groups of biomass samples were then dried in an oven for 48 hours at $60^{\circ} \mathrm{C}$ separately in order that the map product of green biomass can be compared with that of dead biomass.

The LAI (the projected area of all vegetation parts normalized by the subtending ground area) was measured using a LiCor LAI-2000 Plant Canopy Analyzer (LICOR Inc., Lincoln, Nebraska, USA) at $10 \mathrm{~m}$ interval along each transect. The LAI-2000 was shaded when measurements were being taken to reduce the effect of glazing from direct sunshine. At each site, the LAI is the average of 20 automatically calculated LAI values; each was the comparison result of one above canopy reading followed by nine below canopy readings within 2 minutes to avoid atmospheric variation. The LAI discussed in this paper indicated canopy leaf area index.

The measured data were then amalgamated into mean values for each 100 by $100 \mathrm{~m}$ site. We choose a sampling site with an area of 100 by $100 \mathrm{~m}$ because the previous study conducted in the same area determined that the dominant spatial variation of the LAI is at a scale of around $120 \mathrm{~m}$ (He et al. 2007); therefore, by averaging measured data to each $100 \mathrm{~m}$ by $100 \mathrm{~m}$ site, we would be able to avoid autocorrelation within measurements and meanwhile catch the dominant variation of vegetation biophysical properties for the study area.

\subsection{SPOT image acquisition and processing}

A single SPOT $4 \mathrm{HRV}$ image (path 37, row 26) for the study area was acquired on 22 June 2005 (approximately mid-point during the ground truth data collection). The satellite image was geometrically and radiometrically corrected using PCI Geomatica V. 9.1. An accuracy of 0.3 RMS or better (representing approximately $6 \mathrm{~m}$ or less error on the Earth's surface) was ensured in the geometric correction process. Topography distortions were corrected using a digital elevation model 
0 (DEM), obtained from the GNP's GIS database. Atmospheric and radiometric corrections were conducted based on the dark object image subtraction method of Chavez (1988). Even though the atmospheric conditions were not bad during the day that the image was acquired, the aerosol concentrations should approach pristine conditions since the study location and nearby area have a low density of population and less industry contribution, we still conducted an atmospheric correction because the infrared reflectance values of the very dark objects (lakes) were not at or very near zero. Specifically, we first identified a very dark object, a lake in the northeast of GNP within the scene. Next, we observed the lowest value for each band for this lake and assumed these values represent the value contributed by atmospheric scattering for each band. Then, the observed lowest values were subtracted from all digital values for the scene for each band. After the corrections were completed, the digital number (DN) values were converted to reflectance values and the GNP area was clipped from the scene to reduce computing time.

To better detect vegetation signals, the renormalized difference vegetation index (RDVI; Reujean and Breon 1995) and the adjusted transformed soil-adjusted vegetation index (ATSAVI; Baret et al. 1992) were derived from the near infrared (NIR) and red bands to estimate the LAI. We chose these two indices because they have been demonstrated to be best LAI indicators in comparison with other indices for our study region (He et al. 2006). The description about these two indices and the advantage of these indices over other traditional indices can be found in Haboudane et al. (2004) and He et al. (2006). The two indices can be calculated as follows:

$$
\mathrm{RDVI}=\frac{\rho_{\mathrm{NIR}}-\rho_{\mathrm{red}}}{\sqrt{\rho_{\mathrm{NIR}}+\rho_{\mathrm{red}}}}
$$

and

$$
\operatorname{ATSAVI}=\frac{a\left(\rho_{\mathrm{NIR}}-a \rho_{\mathrm{red}}-b\right)}{a \rho_{\mathrm{NIR}}+\rho_{\mathrm{red}}-a b+X\left(1+a^{2}\right)}, X=0.08 .
$$

This study has incorporated both the RDVI and ATSAVI to estimate grassland biophysical parameters. In order for the remote sensing data to better correspond with the LAI values obtained for each site, we extracted and averaged the pixel data within the sites.

\subsection{Analyses linking VI to LAI}

From the 60 sites sampled, 36 were used to build the linear regression models between VI and LAI, and 24 sites were used to evaluate the models (figure 1). The models were validated using the Jack-Knife cross validation procedure. This approach is implemented by withholding one sample and building the regression model using the data from the remaining samples. The process of removing one sample from the dataset was repeated until all samples had been withheld. The relative error, root mean squared error (RMSE) and map accuracy (MA) have been calculated to evaluate the model accuracy for mapping LAI and biophysical data ( $\mathrm{Pu}$ and Gong 2004). These can be computed as:

$$
\text { Relative error }=\frac{x_{i}-\hat{x}_{i}}{x_{i}},
$$




$$
\mathrm{RMSE}=\sqrt{\frac{1}{n} \sum_{i=1}^{n}\left(x_{i}-\hat{x}_{i}\right)^{2}}
$$

and

$$
\mathrm{MA}=\left(1-\frac{\mathrm{RMSE}}{\frac{1}{n} \sum_{i=1}^{n} x_{i}}\right) \times 100,
$$

where $n$ is the site number, $i$ is each site sequence, $x_{i}$ are measured values and $\hat{x}_{i}$ are simulated values calculated from the regression model. After accuracy assessment, the LAI map was developed based on the more accurate regression model.

\subsection{Analyses linking LAI to other biophysical variables}

To develop a biomass and canopy height map, we first performed regression analysis to establish models between the LAI and other biophysical variables (biomass and canopy height) measured from the 36 sites. Then we developed biophysical maps from the LAI map (developed above) based on the established models. We did not estimate biophysical data for the study area directly based on the regression models between biophysical and remote sensing data, in order that we can develop an efficient method to estimate biophysical data from the easily obtained variable (LAI).

The biophysical data from the rest of the 24 sites were used to evaluate the estimation of the biomass and canopy height from the LAI map. The RMSE, relative error and MA have also been calculated to evaluate the accuracy of the maps.

\section{Results}

\subsection{Statistics of LAI data}

The LAI varied considerably across our study area $(C . V .=0.47)$ and had a large range (0.44-3.85), demonstrating that the spatial variation of the grassland vegetation cover was sufficient among study sites to allow us to track changes with biophysical landscape features. Within GNP, the high LAI values (3.85) are generally found in areas with invading grasses, forbs and shrubs, and lower LAI values $(0.44)$ occur in the badlands or lowland areas of high salinity. The mean LAI value of 1.25 indicates that the northern mixed grass prairie has relatively low vegetation cover, only marginally greater than $1 \mathrm{~m}^{2}$ of leaf area per $\mathrm{m}^{2}$ of land area.

\subsection{Regression models between VI and LAI}

The 36 sites were chosen for creating the regression models in this analysis (figure 2).

Two points with very high RDVI values are not outliers, but rather they represent sites with very dense vegetation including invasive grasses and shrubs. Regression results demonstrated that strong relationships exist between LAI and the selected VIs, with ATSAVI having only a marginally higher $R^{2}(0.64)$ than RDVI $(0.63)$ in estimating the LAI. 


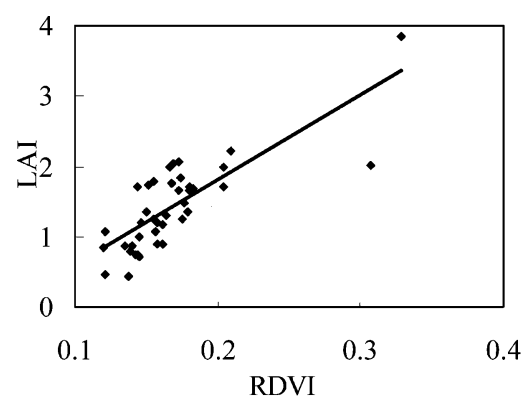

(a)

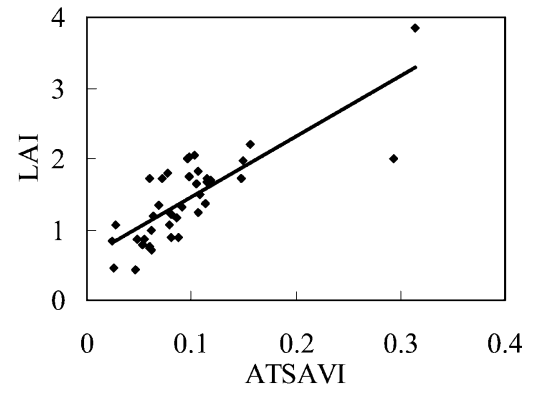

(b)

Figure 2. Regressions of LAI with selected vegetation indices: (a) RDVI; $y=12.149 x-0.63$, $R^{2}=0.63$ and $(b)$ ATSAVI; $y=8.799 x+0.434, R^{2}=0.64 . N=36$ is the number of observations and $p<0.01$.

\subsection{Model accuracy assessment and LAI map}

Based on the linear regression models performed between the selected VI and LAI, we used the rest of the 24 remotely sensed measurements to estimate the LAI. Figure 3 shows the significant relationships $(p<0.01)$ identified between measured LAI and estimated LAI. For both the VIs, the coefficient of $X(0.997$ for RDVI, 0.908 for ATSAVI) indicates that the both regression models give satisfactory estimates of LAI, although it was slightly underestimated. The $R^{2}$ values indicated that ATSAVI (0.489) was only marginally better than RDVI (0.486) in estimating the LAI. The ATSAVI also had a lower average relative error, RMSE, and a higher map accuracy than the RDVI in estimating the LAI for the 20 sites (table 2). This result further indicates that the ATSAVI has a slight advantage in estimating the LAI over the RDVI.

Based on the accuracy assessment results, we produced a LAI map for the west block of GNP using the ATSAVI map. In the final map product (figure 4), a white colour within Park holdings represents low LAI values or decreased vegetation

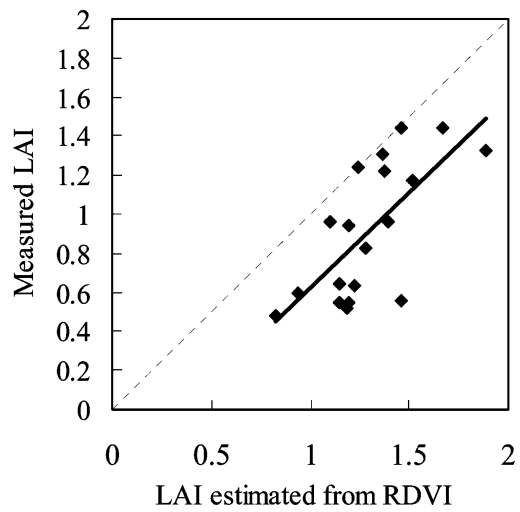

(a)

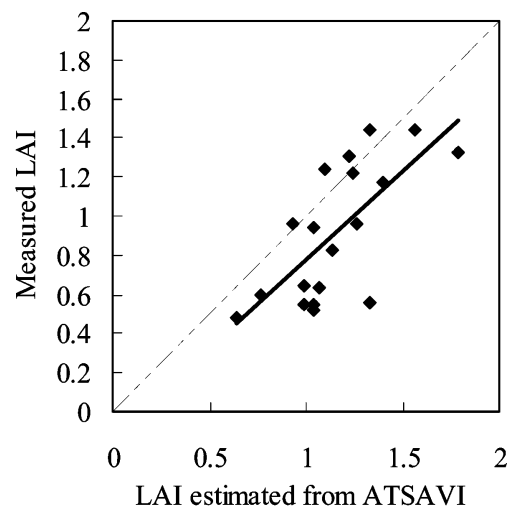

(b)

Figure 3. Relationships between measured LAI and estimated LAI from: (a) RDVI; $y=0.977 x-0.350, R^{2}=0.486$, RMSE $=0.411$ and $(b)$ ATSAVI; $y=0.908 x-0.132, R^{2}=0.489$, $\mathrm{RMSE}=0.297$. Thick solid lines are regression lines and dashed lines are $1: 1$ reference lines, $N=24$ and $p<0.01$. 
Table 1. LAI descriptive statistics.

\begin{tabular}{lcccccc}
\hline Site category & $\begin{array}{c}\text { Number of } \\
\text { sites }\end{array}$ & $\begin{array}{c}\text { Mean } \\
\text { LAI }\end{array}$ & $\begin{array}{c}\text { Range } \\
\text { LAI }\end{array}$ & $\begin{array}{c}\text { Maximum } \\
\text { LAI }\end{array}$ & $\begin{array}{c}\text { Minimum } \\
\text { LAI }\end{array}$ & $\begin{array}{c}\text { Standard } \\
\text { deviation }\end{array}$ \\
\hline Upland & 13 & 1.34 & 1.25 & 1.98 & 0.73 & 0.40 \\
Sloped land & 24 & 1.10 & 1.58 & 2.06 & 0.48 & 0.51 \\
Valley & 22 & 1.38 & 3.41 & 3.85 & 0.44 & 0.74 \\
Total & 60 & 1.25 & 3.41 & 3.85 & 0.44 & 0.59 \\
\hline
\end{tabular}

cover. A light grey colour represents LAI values ranging from 1 to 2, which account for the majority of the Park area. The dark grey represents higher LAI values (2.03.5) or more vegetation covers. In general, areas with the highest LAI values are located along the riparian zone of the Frenchman River, and the lowest LAI values are located towards the north-west portion of GNP and towards the eastern side of GNP and near to the river, where are badlands. The results are reasonable, as the darker areas on the map are associated with areas of higher moisture available for grass growth along the river. The lighter areas on the map are associated with badland topography located towards the upper left area and eastern area near to the river.

\subsection{Relationship between measured LAI and biophysical data}

The linear relationship between measured LAI and biophysical data (i.e. green biomass, dead biomass and canopy height) was significant ( $p<0.01$, figure 5). The 36 sites were used to develop the relationships so they include information from a variety of grass communities. The $R^{2}$ value for the relationships between the green biomass and measured LAI was 0.38 , much lower than those for dead biomass and measure LAI (0.68). Canopy height strongly correlated to the measured LAI $\left(R^{2}=0.58, p<0.01\right)$. These significant relationships indicate that it is possible to estimate biophysical information using LAI data.

\subsection{Biophysical maps and validation}

Biophysical maps were developed from the LAI map using the regression models between biophysical data and measured LAI (figure 6). Figure 6 demonstrates the green biomass map, dead biomass map and canopy height map, respectively. A careful examination of these maps shows that, in general, the three maps accurately represent the biophysical information as explained for the LAI map. A white colour, representing low biophysical quantities, is typically found in badland areas, while the darker colour representing higher biophysical information appears along the river or in cropland. Table 3 presents some simple statistics to interpret the mapped biophysical information against measured data from the rest of the 24 sites. Comparing statistical results in the table, it is apparent that canopy height map results in the highest map accuracy, followed by green biomass, and the least

Table 2. Accuracy assessment of the regression models in LAI estimation.

\begin{tabular}{lccc}
\hline & Average error & RMSE & Map accuracy \\
\hline RDVI & 0.858 & 0.411 & $53.9 \%$ \\
ATSAVI & 0.771 & 0.297 & $66.7 \%$ \\
\hline
\end{tabular}


0

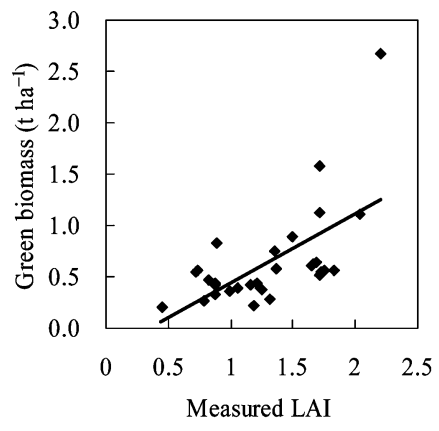

(a)

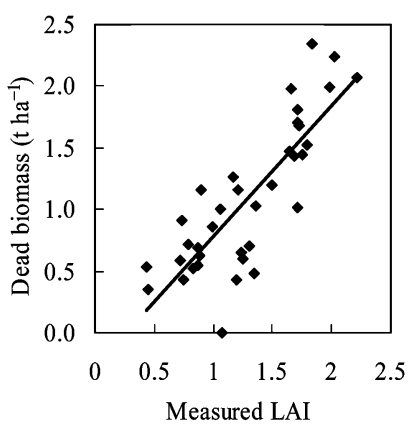

(b)

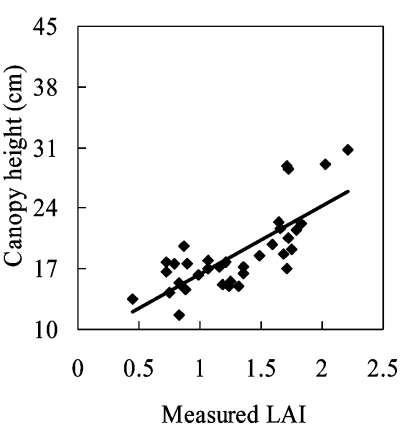

(c) dead biomass is lower in an area with a small amount of litter, and increases in denser litter. In the Park, medium density grassland occupied the majority area with

Figure 5. Regressions between: (a) green biomass; $y=0.5791 x-0.1487, R^{2}=0.38,(b)$ dead biomass; $y=1.066 x-0.2856, R^{2}=0.68$ and $(c)$ canopy height; $y=7.8972 x+8.5325, R^{2}=0.58$; and measured LAI. $N=36$ and $p<0.01$. 

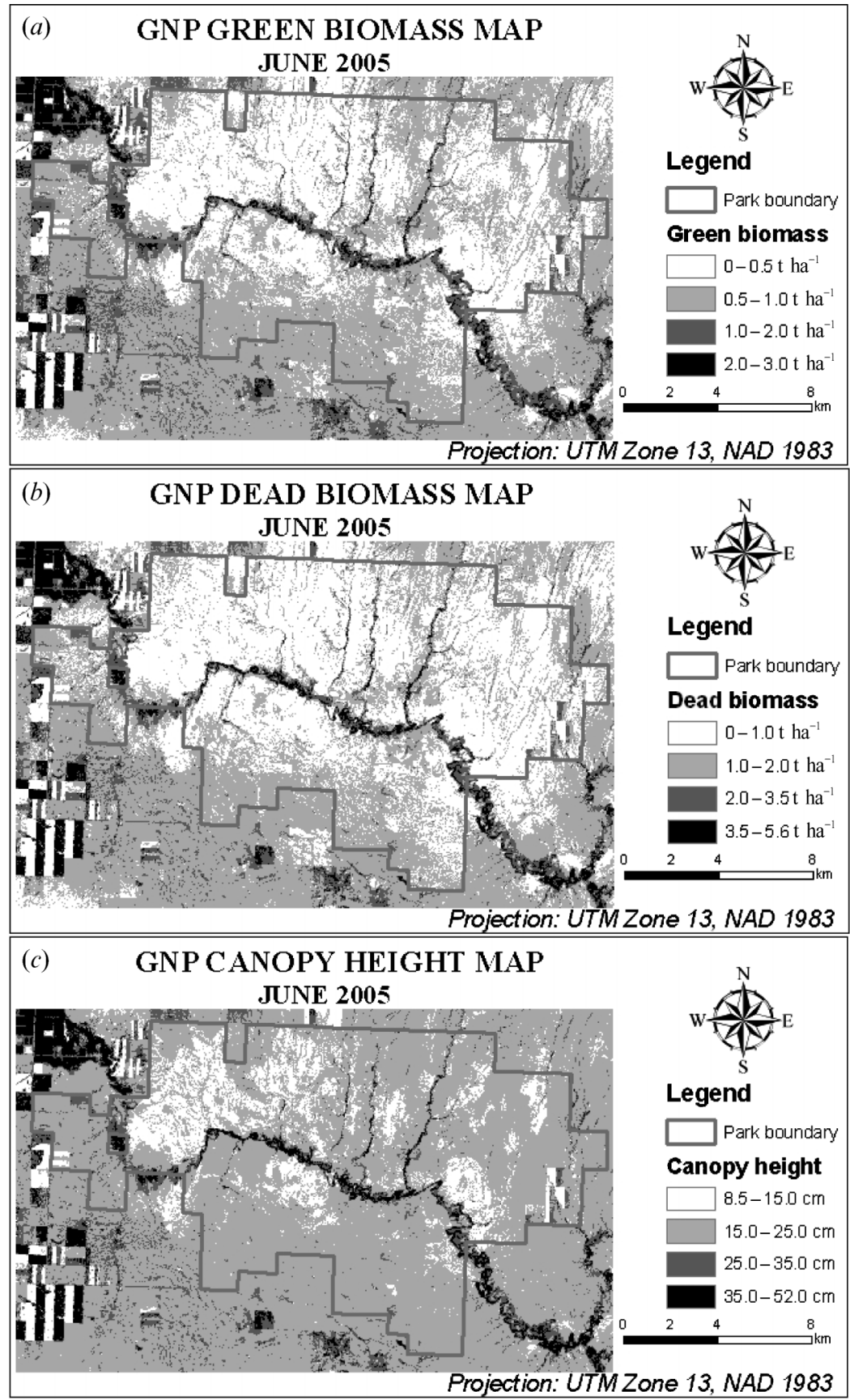

Figure 6. (a) Green biomass map, (b) dead biomass map and (c) canopy height map obtained from LAI map using the regression models between biophysical data and LAI.

a large amount of dead material. This might explain why, when creating the green biomass map, less map error was produced. Conversely, the large amount of dead material in the study area resulted in the least accuracy for the dead biomass map. 
Table 3. Accuracy assessment of the biophysical maps.

\begin{tabular}{lccc}
\hline & Green biomass map & Dead biomass map & Canopy height map \\
\hline Average error & -0.03 & -0.32 & -1.57 \\
RMSE & 0.20 & 0.54 & 3.17 \\
Map accuracy & $55.7 \%$ & $51.2 \%$ & $83.1 \%$ \\
\hline
\end{tabular}

\section{Discussion}

We tested two indices, the ATSAVI and RDVI, to estimate the LAI and to prepare 10 the LAI and biophysical maps for the GNP. The results of the linear regressions demonstrated strong relationships between LAI and both of these selected VIs. However, a detailed assessment of the accuracy of the regression models indicated that the ATSAVI was likely to be better in estimating and mapping the LAI than the RDVI for a northern mixed grassland ecosystem. The accuracy of the LAI map, 15 derived from the ATSAVI was calculated to be $66.7 \%$, and this map represented the spatial distribution of the vegetation for the study area.

The significant relationship between the ATSAVI and LAI found in this study we attribute to the intrinsic properties of the ATSAVI; predominantly its explicit consideration of exposed soil (Baret 1992). In most grassland ecosystems, the cover of a live canopy will be discontinuous, either interrupted by exposed soil in heavily exploited or dry grasslands or by dead vegetation litter in conservation grasslands. Hence, converting reflectance to any characteristic of the biophysical environment in grasslands will profit from explicit consideration of the unvegetated cover. This result also adds support to a previous study conducted in the same area in which the variation in LAI at very small spatial scales was also found to be dependent upon the frequency of bare ground and microtopography (He et al. 2006).

Unmanaged, conservation and native grasslands will always pose a challenge for remote sensing. The relationships between the VIs we used and the LAI were considerably weaker than those observed in previous studies. For example, Haboudane et al. (2004), working on crops, observed $R^{2}$ values ranging from 0.7 to 0.9 for linear models of LAI versus a variety of spectral VIs. Map accuracy at $66.7 \%$ in this study is acceptable, but still low when compared to the results from a

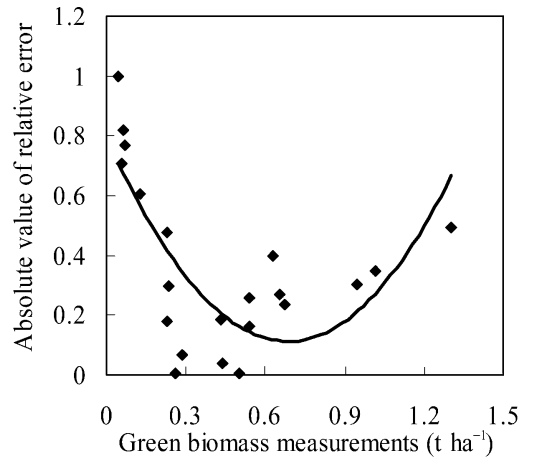

(a)

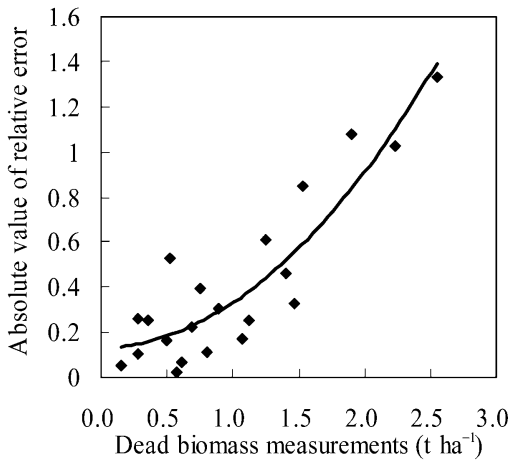

(b)

Figure 7. Absolute values of relative error for: $(a)$ green biomass and $(b)$ dead biomass. 
0 similar study, in which Pu and Gong (2004) mapped the forest LAI where the map accuracy was $74.2 \%$ when using the best method to extract features. The relatively low $R^{2}$ values and map accuracy observed here are likely due to effects such as the registration and scale problems. Validation of our estimates of green and dead biomass from the GNP vegetation maps indicated that, in both cases, our estimates are subject to the heterogeneity of the variance in which, as the mean biomass increases, so does the variation in that biomass. This is to be expected in a heterogeneous vegetation community such as ours (Ehleringer and Field 1993, Tian et al. 2003). This can be resolved by transforming our biophysical parameters prior to statistical analysis. Additionally, with live biomass, our estimates increased as biomass decreased. This could be due to increasing bare soil coverage in low green biomass sites that, despite the ATSAVI's explicit treatment, still introduces error into the reflectance values (Baret and Guyot 1991). Given that we have used a 'book' value for the soil line in our study, we could reduce or eliminate this error by deriving a site-specific soil line for GNP (Broge and Leblanc 2000). Nevertheless, because we can expect the variance in biophysical parameters, such as biomass and productivity, to increase as the mean of these variables increases in natural systems, correlations with reflectance will weaken in more heterogeneous vegetation communities. As we have previously discussed, improvements in reflectance models in grassland ecosystems will come with improving our measures of ground based biophysical features.

The significant relationships between measured LAI and the biophysical data (i.e. green biomass, dead biomass and canopy height) solves the difficulty for mapping biophysical information due to insufficient sampling coverage for GNP. Many of the biophysical measures made in the Park are taken not only to monitor changes in the vegetation community itself, but also to understand the dependencies of the associated faunal community on the vegetation and physical landscape. Research has shown that many fauna are selective for vegetation structure as opposed to composition within ecosystems. The LAI is an effective integrator of grassland structure, incorporating elements of height and density, but is more readily measured than either of these two parameters in a complex sward. Hence, grassland LAI should be a useful tool for spatial modelling, including a currency for measuring gradients for analysis of community structure (McGill et al. 2006). Indeed, GNP is moving forward to incorporate these maps in aid of spatial fire fuels modelling, habitat modelling for species at risk and biomass monitoring for a reintroduced herd of Plains bison. However, the analysis for the relative error demonstrated that the proposed maps should be treated carefully in areas of higher or lower vegetation cover. Scientifically, we should consider avoiding this type of problem in future experiments by measuring more samples from areas with higher or lower vegetation cover. However, the higher (valley) or lower (badland) vegetation cover only occupied 5\% of the study area, which is out of the interests of parks managers, therefore the low estimation accuracy for those areas is not a problem practically. Furthermore, some error propagation might exist when using additional univariate steps for predicting biophysical parameters, even if LAI measure represents a powerful intermediate variable between satellite data and field biophysical data. In this study, we did not consider the residual by further regressing estimated LAI versus biophysical parameters, but unfortunately, it exists. Any further study has to take this issue into account. 
$0 \quad$ References

Asner, G.P., Wessman, C.A., Bateson, C.A. and Privette, J.L., 2000, Impact of tissue, canopy and landscape factors on reflectance variability of arid ecosystems. Remote Sensing of Environment, 74, pp. 69-84.

Baret, F. and Guyot, G., 1991, Potentials and limits of vegetation indices for LAI and APAR assessment. Remote Sensing of Environment, 35, pp. 161-173.

BARET, F., GuYot, G. and MAJOR, D.J., 1989, TSAVI: a vegetation index which minimizes soil brightness effects on LAI and APAR estimation. In Proceedings of IGARSS '89, 12th Canadian Symposium on Remote Sensing, 10-14 July 1989, Vancouver, Canada, 3, pp. 1355-1358.

Baret, F., Jacquemoud, S., Guyot, G. and Leprieur, C., 1992, Modeled analysis of the biophysical nature of spectral shifts and comparison with information content of broad bands. Remote Sensing of Environment, 41, pp. 133-142.

Broge, N.H. and Leblanc, E., 2000, Comparing prediction power and stability of broadband and hyperspectral vegetation indices for estimation of green leaf area index and canopy chlorophyll density. Remote Sensing of Environment, 76, pp. $156-172$.

ChAveZ, P.S., 1988, An improved dark-object subtraction technique for atmospheric scattering correction of multispectral data. Remote Sensing of Environment, 24, pp. $459-479$.

Ehleringer, J.R. and Field, C.B., 1993, Scaling Physiological Processes Leaf to Globe (Boston, USA: Academic).

FrANK, A.B. and KARN, J.F., 2003, Vegetation indices, CO2 flux, and biomass for Northern Plains Grasslands. Journal of Range Management, 56, pp. 382-387.

FrIEDEL, M.H., 1991, Range condition assessment and the concept of thresholds: a viewpoint. Journal of Range Management, 44, pp. 422-426.

Haboudane, D., Miller, J.R., Pattery, E., Zarco-Tejad, P.J. and Strachan, I.B., 2004, Hyperspectral vegetation indices and novel algorithms for predicting green LAI of crop canopies: modeling and validation in the context of precision agriculture. Remote Sensing of Environment, 90, pp. 337-352.

He, Y., Guo, X. and Si, B., 2007, Detecting grassland spatial variation by a wavelet approach. International Journal of Remote Sensing, 28, pp. 1527-1545.

He, Y., Guo, X. and Wilmshurst, J., 2006, Studying mixed grassland ecosystems I: suitable hyperspectral vegetation indices. Canadian Journal of Remote Sensing, 32, pp. 98-107.

Huete, A.R., 1988, A soil adjusted vegetation index (SAVI). International Journal of Remote Sensing, 9, pp. 295-309.

McGill, B.J., Enquist, B.J., Weiher, E. and Westoby, M., 2006, Rebuilding community ecology from functional traits. Trends in Ecology and Evolution, 21, pp. 178-185.

Pu, R. and Gong, P., 2004, Wavelet transform applied to EO-1 hyperspectral data for forest LAI and crown closure mapping. Remote Sensing of Environment, 91, pp. 212224.

Qi, J., Chehbouni, A., Huete, A.R., Kerr, Y.H. and Sorooshian, S., 1994, A modified soil adjusted vegetation index. Remote Sensing of Environment, 48, pp. 119-126.

ReujeAn, J. and BREON, F., 1995, Estimating PAR absorbed by vegetation from bidirectional reflectance measurements. Remote Sensing of Environment, 51, pp. 375-384.

Richardson, A.J. and Wiegand, C.L., 1977, Distinguishing vegetation from soil background information. Photogrammetric Engineering and Remote Sensing, 43, pp. $1541-1552$.

45 Rouse, J.W., HaAs, R.H., Schell, J.A., Deering, D.W. and Harlan, J.C., 1974, Monitoring the Vernal Advancement of Retrogradation of Natural Vegetation, NASA/GSFC, Type III, Final Report, Greenbelt, MD, USA, pp. 1-371. Saskatchewan Soil Survey 1992, Grasslands National Park Soil Survey, University of Saskatchewan, Saskatoon, Saskatchewan, Canada. 
0 Stohlgren, T.J., Coughenour, M.B., Chong, G.W., Binkley, D., Kalkhan, M.A., SChell, L.D., Buckley, D.J. and BerRy, J.K., 1997, Landscape analysis of plant diversity. Land Ecology, 12, pp. 155-170.

Tian, Y., Wang, Y., Zhang, Y., Knyazikhin, Y., Bogaert, J. and Myneni, R.B., 2003, Radiative transfer based scaling of LAI/FPAR retrievals from reflectance data of different resolutions. Remote Sensing of Environment, 84, pp. 143-159. 